even operate under an unfamiliar Mental Health Act.

In many cases, the travel and hotel expenses are considerable for the SHO's to pay. If they do eventually pass the exam, the letter of congratulations asks straight away for the membership fee. It leaves an impression that all the College is interested in is money, and is lacking in human compassion and thought for their SHO's.

The SHO's do not seem to have an effective voice in the College. In general psychiatry, we now have effective users' groups representing the patients. We need a similar effective voice representing the SHO's. My SHO's said that they would be most grateful if I would write to the College on their behalf.

If the College is experienced by the trainees as insensitive to their feelings, this should be a matter of general concern for the membership. I wonder if there are others in the College, whether affiliates, or members who also feel that there is a need to alter the MRCPsych exam arrangements with more thought and compassion for the SHO's position?

Richard Lucas Consultant Psychiatrist, St Ann's Hospital, 63 Ossulton Way, London N2 0JY

\section{Points in response to letter from Dr Lucas}

In allocating candidates to clinical centres, the criteria are that they are not sent to a centre where they have previously worked, where they are currently working or where they have been examined before

The College is dependent upon the centres which volunteer their resources to accommodating the clinical examinations and although, geographically, these are spread as widely as possible it inevitably can mean that candidates are required to travel to a centre that meets the allocation criteria. Candidates are made aware of this when entering for the examination.

These criteria were put in place and continue to be operated in the best interests of the candidates. In implementing them, the aim is to ensure that all candidates have an equal chance in the assessment, and that no one could construe that they have been either advantaged or disadvantaged by having had previous contact with the patients with whom they will be presented during the clinical examination.

Every effort is made to allow candidates sufficient time to make their travel plans to the clinical centre to which they have been allocated. The minimum time which candidates will have to arrange their travel and, if necessary, accommodation is 2 weeks.

Professor O. A. Oyebode Chief Examiner

agree entirely with Dr Lucas that SHOs need and deserve an effective voice within our College. We have two mechanisms in place to achieve this. The Inceptorship scheme is open to all trainees intending to take the MRCPsych examination and puts them in contact with the College, provides them with free or subsidised subscription to the College Journals and gives them regular information about relevant College events. In addition, SHOs form an important part of the Collegiate Trainee Committee (TC) membership. Through the CTC, SHOs (as well as specialist registrars) are represented on all key College committees.

Professor Cornelius Katona Dean

\title{
the college
}

Health include: the Homeless Mentally III Initiative, which set up outreach teams and hostels, and the inquiry into mental health of Black people in the UK. Mr Bowis launched the Spectrum of Care, conferences of users and purchasers in 24-hour nursed care; the medium secure beds expansion of the Glancy Report; and the suicide prevention strategy, and departmental support of the Defeat Depression Campaign. He has raised the profile of child and adolescent mental health and secured significant increases in funding for mental health services; he reviewed the future of high-security hospitals and the care of people with personality disorder and took a number of initiatives to improve the care of people with learning disabilities. While supporting the WHO global campaigns on mental health and on epilepsy, he opened doors to Health Ministers in various parts of the world and helped mental health professionals influence the health priorities of their governments. John Bowis is a great ally for mental health, who has played a substantial role in stimulating international and national political will to improve mental health services throughout the world. Member of the European Parliament. He gives his time freely to the mental health cause, within the European Parliament, within the UK and across the world. He has been an active contributor to a number of College conferences and events. Some examples of mental health initiatives during his time as Minister for

\section{Lord Melvyn Bragg}

The work of Lord Melvyn Bragg, FRSL, DLitt, MA, FRTS, television presenter, novelist and broadcaster, and currently President of MIND, will be very familiar to most people. Lord Bragg's name is synonymous with the arts in general. He has worked in broadcasting since 1961 and is currently Controller of Arts and Features at London Weekend Television (LWT), Editor and Presenter of The South Bank Show and Executive Producer of several other arts' strands. He also writes for numerous publications. He is President of the National Campaign for the Arts, a Governor of the London School of Economics and Political Science and Chancellor of Leeds University. He was made a Life Peer in 1998. In 2001, he won the Prix Italia Special Award for 25 seasons of The South Bank Show and, among many other achievements, has received Honorary Doctorates and Fellowships from numerous academic organisations.

Lord Bragg has been involved with MIND in Carlisle for 16 years and became President of the national organisation in 2001. His awareness of the distress experienced by those with mental illness and of the stigma surrounding mental health has strengthened his resolve to campaign on mental health issues in the House of Lords and to raise awareness of the extent of the problem.

\section{Professor John Cox}

Professor John Cox can be justifiably singled out as an individual whose contribution has been exceptionally distinguished across various medical disciplines. His activities have been extremely wideranging over a very long period covering 
research, teaching and service delivery, and he has made significant contributions to the development of the Department of Psychiatry and the postgraduate school in the advancement of science, teaching and research at Keele University. As the Chairman of its Department of Psychiatry for two periods, he has developed various specialities in the field of mental health, and colleagues in the NHS consider his contribution to be remarkable among other professors of psychiatry in the UK. He gained a national reputation for his interest and research in perinatal and transcultural psychiatry in the 1980s, and a sustained output of research papers and teaching activity secured his international reputation by the early 1990s. His national and international fame was subsequently enhanced by his election to the Presidency of the Marce Society, an international organisation for the prevention and treatment of perinatal illness. Professor Cox has also developed the Diploma and MSc in General Psychiatry at Keele University which is highly regarded by trainee psychiatrists from around the world. In 1992, he was elected Dean of the College and served in this capacity with the utmost capability and distinction. In 1999, he was elected President of the College. As President he made his mark by being one of the most approachable, innovative, forward-looking leaders of the profession who led the College in the globalisation of mental health. Professor Cox was recently elected as Secretary General of the World Psychiatric Association (WPA).

\section{Dr Pearl Hettiaratchy, OBE}

Pearl Hettiaratchy has brought distinction to herself, the College and the psychiatric profession through her contributions to the NHS over a period of 30 years. Her primary contributions have been within the field of old age psychiatry, where she has pioneered the establishment and development of services, first in Portsmouth and later in Winchester. She has enthused others and educated people of many backgrounds to achieve good practice. She has been determined and devoted in her work; brave and selfless, never fearing to take unpopular stances when she knew these to be in the interests of her patients who were not able to speak for themselves. By her activities and her example, she has improved the lot of old people with mental illness, and their families, and those who work with them professionally. She has advised Ministers in the UK and in Sri Lanka on the needs of such services and is a tireless supporter of charities in the field. She has remained active in medico-legal matters and in medical politics; her advice and opinion is respected on a range of issues including those arising in multi-ethnic populations, the ethics of health care and the identification and support of doctors in difficulty. Dr Hettiaratchy has long been involved with College activities and has also served as Vice-President. She retired from active professional work this year, but continues a busy diary of advisory and voluntary work.

\section{Dr Benedetto Saraceno}

$\mathrm{Dr}$ Benedetto Saraceno is a psychiatrist known internationally for his contribution to the advancement of mental health. After receiving his post-doctoral degree in psychiatry, he subsequently gained a qualification in Public Health and Epidemiology from the Mario Negri Institute for Pharmacological Research, Milan, where he became Chief of the Psychiatric Unit the beginning of a very distinguished career. During the 1990s, he contributed to a number of WHO projects in countries in South and Latin America, which eventually led to his appointment as Head of the Laboratory of Epidemiology and Social Psychiatry and Director of the WHO Collaborating Centre for Research and Training in Mental Health at the Mario Negri Institute. He also worked in Geneva as Programme Manager in the Division of Mental Health and Prevention of Substance Abuse at the WHO. With the reorganisation of the WHO, he was appointed Director of the Department of Mental Health. He convinced the WHO to designate 2001 as the WHO Mental Health Year, and to dedicate the World Health Report of 2001 to mental health. This was the first time that mental health attained such a prominent position in the WHO Programme of Action. His initiative led to a memorandum of understanding between the College and WHO for research training fellowships. In 2001, Dr Gro Harlem Brundtland, Director General of the WHO, addressed the annual conference of the College and presented the outline of the WHO report for the first time in a public forum, with an invitation for closer collaboration between the WHO and the College.

\section{Patients as parents. Addressing the needs, including safety, of children whose parents are mentally ill}

\section{CR105 June 200232 pp £7.50}

This document provides a fully-referenced and practical summary of key issues involving the interactions and influences between parental psychiatric disorder and child mental health and well-being. It promotes an ecological approach, in which mental illness is firmly embedded within a family and social context. The links between poverty, mental ill health, discrimination and social exclusion are compelling, and any attempt to improve the life chances for patients who are parents and their children must be based on a good understanding of the needs of children and their mentally ill parents.

There is an introduction followed by six sections that cover: Family Influences; Parenting; Child Maltreatment; Special Circumstances (parental self-harm and hospitalisation); Implications for Practice; and Improving Services. A reference list together with a list of additional key texts is included. Practice guidelines provide concise, practical summaries of important topics.

The intention is to raise awareness and promote good practice nationally - how psychiatrists can help in a situation where people who have a psychiatric disorder or abuse drugs or alcohol also have childcare responsibilities or contact with dependant children. The emphasis is on roles and responsibilities for psychiatrists across all faculties, and the need for closer, more effective collaboration within teams and between other services and agencies.

The fact that services for children and adults are currently delivered quite separately means that this report will be of relevance to a wide readership, including those in non-mental health services, those with responsibility for supporting families, the voluntary sector, service users and all those with service planning and policy development responsibilities.

The introduction provides an overview of key issues, such as the scale of the problem (for example, the number of patients who are parents), the impact of parental mental illness on children's adjustment and a consideration of possible mechanisms. The broad continuum in the quality of child-parentprofessional interaction is described. While many parents cope exceptionally well, despite the presence of significant mental health problems, and some children show few, if any, adverse effects, the presence of a mental illness in a parent can adversely affect the way in which that parent accomplishes the tasks and responsibilities of parenthood, and similarly the stresses of parenthood can precipitate or exacerbate mental ill-health. Furthermore, children, especially those with chronic physical, developmental or emotional disorders, can precipitate or exacerbate parental mental illness.

A systemic conceptual framework is provided in the family section to contextualise interactions between parents and children - the Family Model. This integrated, ecological model of influences and interactions between mental illness, parenting, family relationships, child development, and environmental risk factors and protectors was developed in the Department of Health-sponsored training materials on the impact of parental mental illness on children, entitled 'Crossing Bridges'. This model emphasises 